\title{
Remote Monitoring and Control of Boat Using Lora Technology
}

\author{
R Nagarajan ${ }^{1}$, Kamlesh $\mathrm{Kumar}^{2}$, Chandan Kumar ${ }^{3}$, Pawan Kumar ${ }^{4}$
}

\begin{abstract}
${ }^{1}$ Professor, Department of Electrical and Electronics Engineering, Gnanamani College of Technology, Tamilnadu, India. 2,3,4 UG. Students, Department of Electrical and Electronics Engineering, Gnanamani College of Technology, India.
\end{abstract}

\begin{abstract}
This work is a prototype boat that can travel in water. This robot is powered by rechargeable battery. The direction of the robot can be precise by an $R F$ remote. This can be moved forward and reverse direction by using geared motors, also this robot can take sharp turnings towards left and right directions. In this work the LPC2148, DC Servomotors, RF Technology; L293D HBridge is used to drive the DC Servomotor. A high sensitive camera is also interfaced to capture the surrounding things and also to transmit to the remote place. The RF modules used here are STT-868 MHz Transmitter, STR-868 MHz Receiver. The three switches are connected to the RF transmitter through RF Encoder. The encoder constantly recites the position of the switches and permits the data to the RF transmitter and the transmitter transmits the data for further process.
\end{abstract}

Keywords- RF Module, LPC2148, DC Servomotor, ATmega 16.

\section{INTRODUCTION}

In our daily life many people travel in boat. Sometime any atmospheric problem are occurred like landscape, tsunami etc. that time people can't be communicate for their safety purpose. This past of robotics is secured with the antiquities of technology, science and the basic principle of movement, electricity, even pneumatics and hydraulics would also be measured a part of the history of robotics [1]

The timeline presented is therefore far from complete. Robotics now signifies one of manhood's greatest activities and is the single greatest effort of mankind to produce an artificial, feeling being. It is only in recent years that constructors are building robotics progressively available and possible to the overall public. The attention of this timeline is to deliver the booklover with a general overview of robotics with a focus more on traveling robots and to give an gratitude for the inventors and innovators in this field who have helped robotics to become what it is today, the science and technology behind the design and manufacturing and application of robots [2]-[4].
The radio frequency (RF) and wireless have been around century of old development in the field of communication over a long range, for wireless radio growths in the early 20th century. In December 1901, Marconi done his most protruding experimentation, where he successfully transmitted Morse code from Cornwall, England, to St John's, Canada. The ability of a system to operate autonomously, carrying out tasks that are unachievable by conventional machines, opens up an enormous range of applications that are uniquely suited to automated processes requiring wireless communication over a range. Such systems need to operate over a wireless network in certain environments and achieve certain tasks [5]-[7].

The wireless automation is simply referred to radio frequency or GSM communication over the IoT (internet of things) platform. However, the choice of which communication platform (network based or radio frequency based) to be used is largely dependent on the nature of task to be carried out and what parameters are concerned with the process and particularly the cost effective nature of each platform to be used. Such parameters as mentioned above have very vital effects over the nature of design. For instance, a very important parameter is the range over which communication is to be established [8]. This determines largely what decisions are to be made as regards the operation of the system. This is because a lot of other parameters will vary as the range increases or decreases. These parameters are tied primarily to the communication and the range of communication such as cost, signal strength, receptivity and the number of processes to be controlled or operated. On the event of comparing varying effects of these mentioned parameters [9],

The RF communication is preferred for short range wireless communication. A maximum range of one hundred meters has been chosen as the required range over which communication is to be established and will determine the circumference of the work. In today's world as in, wireless communication over the embedded system platform has become a wide sphere of technological possibilities as very intelligent or complex 
processes requiring high precision in operation can be fully operated wirelessly, even from the comfort of one's home [10],[11].

The proposed work implemented in wireless controlled robotic boat to travel in water. This work is done by using RF technology for audio transmission as well as reception. The boat is powered by $9 \mathrm{~V}$ rechargeable battery. The path of the boat will be precise by an RF remote. This can be moved forward and reverse direction. Also this robot will take severe turnings to left and right directions. There are various type of recent technology are being implemented such as experiments in robotic boat localization in Oct. 2007 [12],

The RF based wireless boat control. This boat circuit uses the RF module ( $\mathrm{T} x / \mathrm{Rx}$ ) for building a wireless remote, which would be used to enterprise an output from a long distant place. RF module, as the name advises, uses radio frequency to send signals. These signals are communicated at a particular frequency and a baud rate. A receiver can receive these signals only if it is shaped for that frequency. A four channel encoder/decoder couple have also been used in this system. The input signals, at the transmitter side, which are taken by four switches while the outputs are supervised on a set of four LEDs consistent to each input switch. The circuit can be used for scheming remote application control system. The outputs from the receiver can drive corresponding relays connected to any household appliance [13]-[15].

The RF is a frequency or degree of oscillation within the sort of about $3 \mathrm{~Hz}$ to $300 \mathrm{GHz}$ This range matches to frequency of irregular current electrical signals used to harvest and perceive radio waves. The electrical currents that vacillate at RF have unusual as sets not communal by direct current signals. One such stuff is the ease with where it will ionize air to produce a conductive path through air. This property is broken by 'high frequency' units used in electric arc welding. Another special property is an electromagnetic force The RF current to the surface of conductors is also driven by electromagnetic force, known as the skin effect [16],[17].

\section{BLOCK DIAGRAM}

Initially considering the entire system come across two different section, namely, transmitter section and receiver section. The robot is a programmable mechanical device that will accomplish tasks and cooperate with its atmosphere, In transmitter part a data encoder and RF transmitter is used. In transmitter section consist four push buttons to trip the robot; this four buttons are associated with encoder with respect to ground. When will press any button encoder, will have a digital squat signal and then applied this signal successively to RF transmitter [18]. The figure 1 shows generalized diagram of robotic boat system.

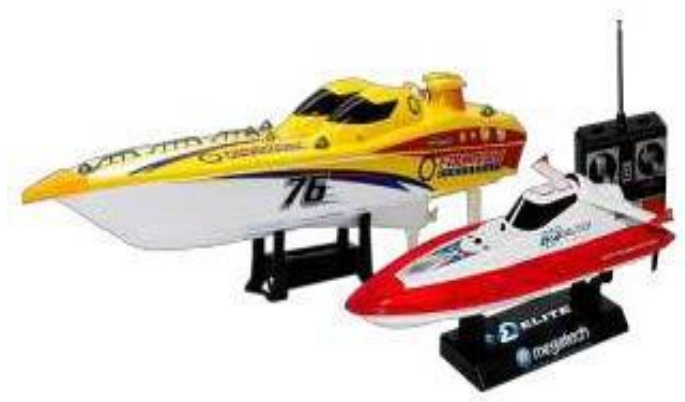

Fig.1: Generalized Diagram of Robotic Boat System.

The encoder IC HT12E encodes data or signal or converting into serial form and then sends this signal by using RF transmitter into the environment. At the receiver end used RF receiver to receive data or signal and then applied HT12D decoder [19]. This decoder IC converts all the received serial data parallel and then send these decoded signals to motor drive IC. According to received data robots runs by using two DC motor in forward, reverse, left, right and stop direction. The figure 2 shows block diagram of robotic boat system.

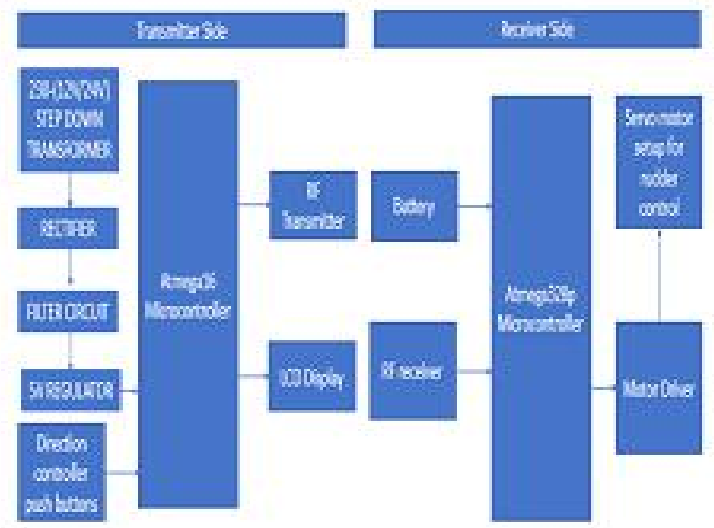

Fig.2: Block Diagram of Robotic Boat System

\section{TRANSMITTER and RECEIVER}

Transmitter section: The RF transmitter STT-468 is ideal for remote control applications where low cost and longer range is required. The transmitter operates from a 5-12V supply, it marks ideal for many battery-powered applications. The transmitter services a SAW-stabilized oscillator, certifying precise frequency control for best range routine. The manufacturing-friendly SIP style package and low-cost make the STT-468 suitable for high volume applications [20]. The digital data is collected from the CMOS. This input is CMOS compatible and should be driven with CMOS level inputs the VCC is the Operating voltage for the transmitter. The VCC should be avoided with a $.02 \mathrm{uF}$ ceramic capacitor and filtered with a 
4.7uF tantalum capacitor. Noise on the power supply will damage transmitter blare performance. The ANT is 50 ohm antenna output. Their antenna port side impedance touches output power and harmonic emissions. Antenna can be single core wire of approximately $17 \mathrm{~cm}$ length or $\mathrm{PCB}$ dash antenna.

B. Receiver section- Here all the data is received by the $\mathrm{RF}$ receiver from the antenna pin and this data is offered on the data pins. The two Data pins are provided in the receiver module. Thus this data can be used for further applications [21]. The figure 3 (a) and (b) shows pin diagram of RF transmitter and receiver STR-433Mhz.

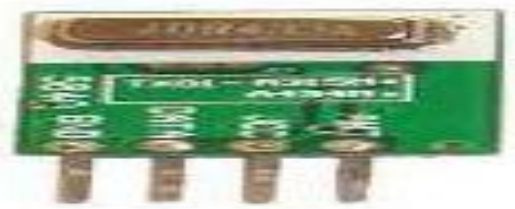

Fig.3 (a) Pin Diagram of RF Transmitter STR

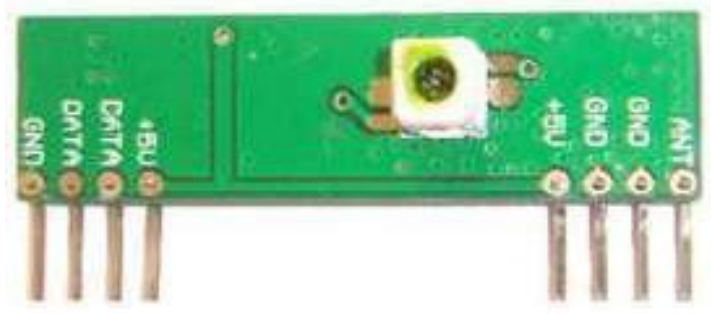

Fig.3 (b) Pin Diagram of RF Receiver STR

The RF transmitter and receiver have the advantages such as: TR Not blocked by common materials: It can penetrate most solids and pass through walls. Longer range It is not sensitive to the light and It is not much sensitive to the environmental changes and weather conditions [22].

\section{SERVO MOTOR AND CONTROLLER}

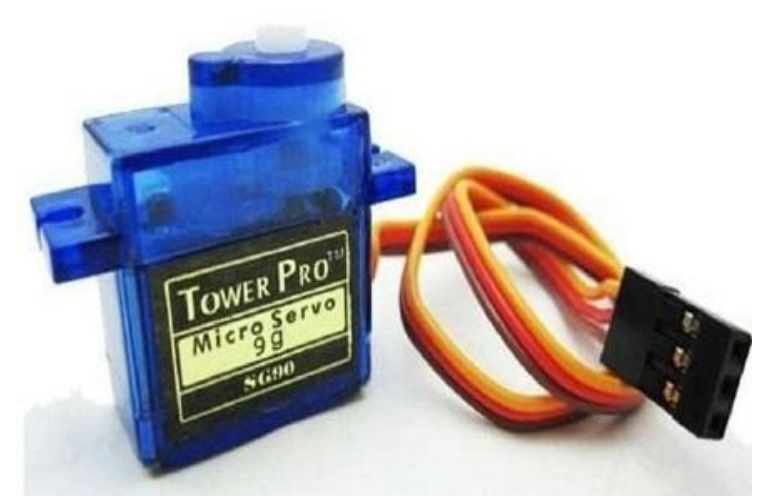

Fig.4 Servo Motor and Controller

The servo motor is an electrical device which can push or rotate an object with great precision. This motor is to revolve and object at some specific angles or distance, then use servo motor. This is just made up of simple motor which run through servo mechanism [23]. The motor which used DC supply for their operation is called DC servo motor, and if it operates by AC power supply then it is called AC servo motor. These motors have very high torque in a small and light weight packages. Because of these features they are being used in many uses like toy car, RC helicopters and planes, Robotics, Machine etc. The figure 4 shows servo motor with its controller [24].

The servo motors are rated in $\mathrm{kg} / \mathrm{cm}$ (kilogram per centimeter) mostly servo motors are rated at $3 \mathrm{~kg} / \mathrm{cm}$ or $6 \mathrm{~kg} / \mathrm{cm}$ or $12 \mathrm{~kg} / \mathrm{cm}$. This $\mathrm{kg} / \mathrm{cm}$ tells how much weight the servo motor can lift at a particular distance. For design: A $12 \mathrm{~kg} / \mathrm{cm}$ servo motor should be able to lift $12 \mathrm{~kg}$ if the load is suspended $2 \mathrm{~cm}$ away from the motors shaft, while superior the distance then lesser the weight carrying ability. The position of a servo motor is decided by electrical signal and its circuitry is positioned near the motor [25].

It is a closed loop system where it uses feedback system to control indication and final position of the shaft, the device is precise by a feedback signal generated by matching output signal and reference input signal. There reference input signal is compared to reference output signal and the third signal is creates by feedback system. And the third signal work as input signal to control device [26]. This signal is extant as long as feedback signal is generated and there is difference between reference input signal and reference output signal. So the key duty of servomechanism is to maintain output of a system at wanted value at presence of noises [27].

The servo contains of a Motor (DC or AC), a potentiometer, gear assembly and a controlling circuit. Primarily we use gear assembly to reduce RPM and to increase torque of motor. Say at initial position of servo motor shaft, their location of the potentiometer handle is ready in such a way that there is no electrical signal produced at the output port of the potentiometer. After words an electrical supply is given to alternative input station of the error detector amplifier. And then difference between these two signals, one comes from potentiometer and alternative comes from other source, will be handled in feedback mechanism and output will be delivered in term of error signal. This error signal acts as the input for motor and motor starts rotating [28].

Now motor shaft is connected with potentiometer and as motor revolves so the potentiometer and it generates a signal. So as the potentiometer's angular position changes and its output feedback signal changes. After some time instant the location of potentiometer extents at a location that the output of potentiometer is same as external signal provided. At this condition, there will not be output signal from the amplifier to the motor input as there is no 
difference between external realistic signal and that signal produced at potentiometer, and in this condition motor stop rotating [29]. The figure 5 shows potentiometer for servo motor control.

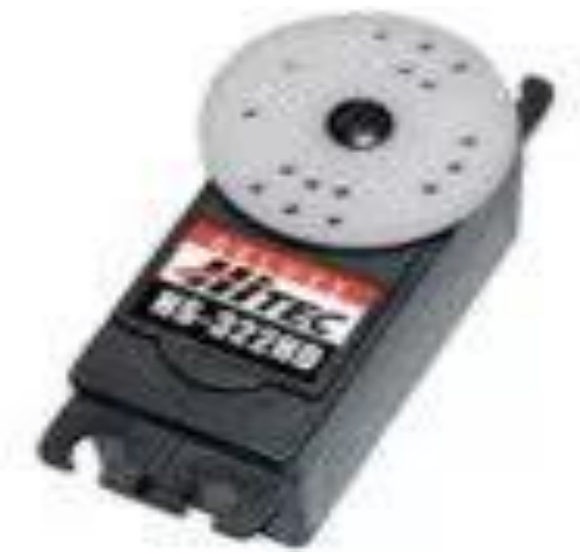

Fig.5 Potentiometer for Servo Motor Control

The all motors have three wires coming out of them. Out of all two will be used for Supply (positive and negative) and one can be used for the signal that is to be sent from the MCU. The servo motor is controlled by PWM (Pulse with Modulation) which will be delivered by the control wires. There will be a least pulse, a full pulse and a repetition rate. The servo motor can turn 90 degree from either direction form its neutral position. The servo motor supposes to see a pulse every 30 milliseconds (ms) and the length of the pulsation will control how far the motor turns. For a case, a $1.8 \mathrm{~ms}$ pulsation will make the motor turn to the $90^{\circ}$ position, such as if pulse is shorter than 1.8 ms shaft moves to $0^{\circ}$ and if it is longer than $1.8 \mathrm{~ms}$ than it will turn the servo to $180^{\circ}$ [30].

\section{POWER SUPPLY and MICROCONTROLLER}

The power supply circuit contains a step-down transformer which is $230 / 12 \mathrm{v}$. In this circuit 4diodes are used to route bridge rectifier that supplies pulsating $\mathrm{dc}$ voltage and then fed to capacitor mesh and the output voltage which comes from rectifier is fed to filter to disregard any a.c. components present even after rectification. The strained DC voltage is supply to controller to produce 10 to $12 \mathrm{v}$ constant DC voltage. $230 \mathrm{~V}$ AC power will be adapted into 12V AC (12V RMS value wherein the peak value is around $17 \mathrm{~V}$ ), whereas the mandatory power is $5 \mathrm{~V} \mathrm{DC}$; for this purpose, $17 \mathrm{~V} \mathrm{AC}$ power must be mostly converted into DC power then it will stepped down to the $5 \mathrm{~V}$ DC. AC power can be transformed into DC by rectifier. Here different types of rectifiers is used, such as half-wave rectifier, full-wave rectifier and bridge rectifier. Due to the benefits of the bridge rectifier over the half and full wave rectifier, the bridge rectifier is commonly used for transforming AC to DC. The figure 6 shows the circuit of a power supply which transforms an ac source to a de source [31].

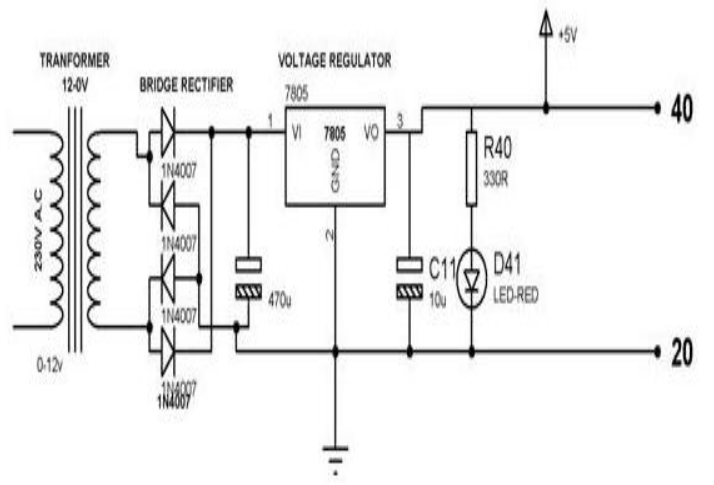

Fig.6 Power Supply Circuit

The AVR is a family of microcontrollers developed by Atmel beginning in 1996. These are called modified Harvard architecture 8bit RISC single-chip microcontrollers as opposed to one-time programmable ROM, EPROM, or EEPROM used by other microcontrollers at the time. The AVR architecture was perceived by two students at the Norwegian Institute of Technology (NTH).

The original AVR MCU was developed at a local ASIC house in Trondheim, Norway, called Nordic VLSI at the time, now Nordic Semiconductor, where Bogen and Wollan were working as students. It was a $\mu$ RISC (Micro RISC) and was accessible as silicon IP/building block from Nordic VLSI. When that technology is vended to Atmel from Nordic VLSI, the internal building was further developed by Bogen and Wollan at Atmel Norway, a secondary of Atmel. The engineers functioned closely with compiler at IAR Systems to guarantee that the AVR instruction set provided effective compilation of high-level languages [32]

Atmel says that the name AVR is not an abbreviation and does not stand for whatever in actual. The inventers of the AVR give no conclusive solution as to what the term "AVR" stands for conversely, it is commonly accepted that AVR stands for Vegard's RISC processor, the use of "AVR" in this article usually refers to the 8-bit RISC line of Atmel AVR Microcontrollers. Among the first of the AVR line is AT90S8515, which has 40-pin DIP package structure in the same pin out as 8051 microcontroller, which includes the external multiplexed address and data bus.

The following are the features of the microcontroller such as: Multifunction, bi-directional general-purpose I/O ports with configurable, built-in pull-up resistors. Multiple internal oscillators, including $\mathrm{RC}$ oscillator deprived of external parts. Interior self-programmable instruction and flash memory capacity is up to $256 \mathrm{~KB}(384 \mathrm{~KB}$ on XMega). In-system programmable using serial/parallel 
low-voltage exclusive interfaces or JTAG. Optional boot code section with autonomous lock bits for protection. On-chip repairing (OCD) provision through JTAG or debug WIRE on most devices. The JTAG signals (TMS and TCK) are multiplexed on GPIOs. This pins is arranged to purpose as JTAG or GPIO depending on the venue of a fuse bit, which can be programmed via ISP or HVSP. By default, AVR and JTAG come with the JTAG interface enabled. Debug WIRE uses the /RESET pin as a bi-directional communication channel to contact on-chip debug circuitry. It is present on devices with lower pin counts, as it only requires one pin [33].Internal data EEPROM up to $4 \mathrm{~KB}$. Internal SRAM, $16 \mathrm{~KB}$ (32 KB on $\mathrm{X}$ Mega). External $64 \mathrm{~KB}$ little Indian data space on positive models, including the Mega8516 and Mega162. The figure 7 shows the AT mega162 microcontroller pin diagram

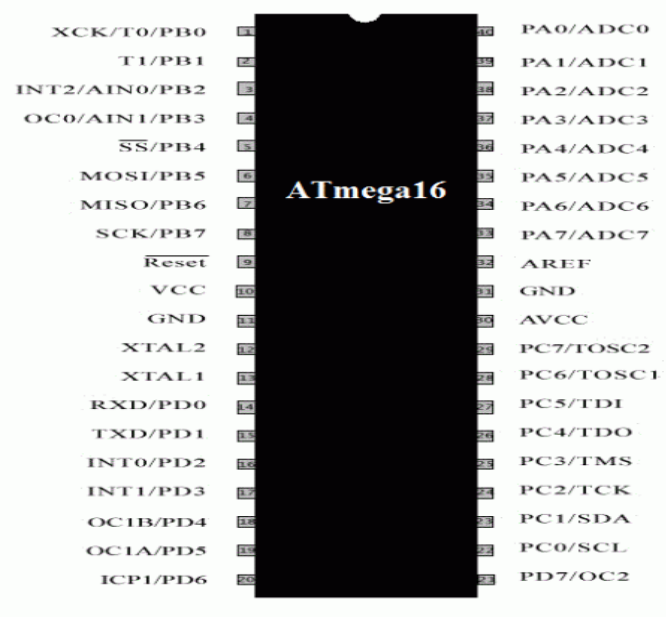

Fig.7 AT megal62 Microcontroller Pin Diagram

The Liquid crystals are a phase of matter whose order is in-between that of a liquid and that of a crystal. The particles are naturally rod shaped living matters it is nearly 25 Angstroms in length and this ordering is a task of temperature. Applied electric fields can be controlled by molecular orientation. LCD is made by two sheets of polarizing material with the liquid crystal solution between it. An electric current supplied over the liquid heritages the crystals to bring into line so that light cannot pass through them, Results on display of character as per the realistic voltage in its data lines. The carter is provided to drive the LCD. It supplies the data of display which transferred from the microcontroller in the internal display RAM and generates dot matrix liquid crystal driving signals. Each bit data of display RAM links to on/off state of a liquid crystal display. LCD is used in widespread applications due to the following reasons: The declining prices of LCDs, ability to display numbers, characters, and graphics, incorporation of a stimulating regulator into the $\mathrm{LCD}$, thus, releasing the CPU of the duty of revitalizing the LCD, and ease of programming for characters and graphics [34]. The figure 8 shows the image of a 16x2 LCD display.

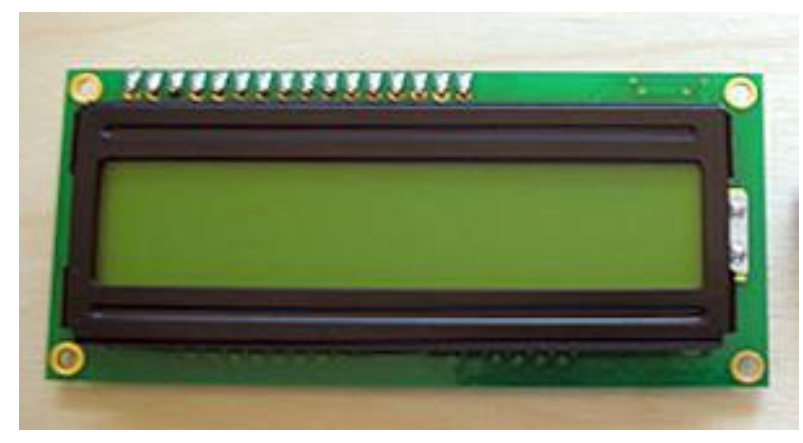

Fig.8-16x2 LCD display

\section{CONCLUSION}

There are number of wireless technologies are available having different features, applications and limitations. From above analysis it will be very useful for wireless communication, these sources are easily available now days, and hence the proposed system becomes more cost effective and economical. The proposed system will use oceanic research centers application for interfacing RF module and controller.

\section{REFERENCES}

[1] Jan sliwka, pierre-henri reilhac, Richard leloup, Pierre crepier, henry demalet, Patrick sittaramane" autonomous robotic boat of ensieta", wrsc/irsc2009.

[2] R.Nagarajan and M,Saravanan, "A Carrier - Based Pulse Width Modulation Control Strategies for Cascaded Multilevel Inverter," International Review on Modeling and Simulations (IRMOS), Vol 6.No1, pp-8-19, Feb. 2013.

[3] M.Elangovan, R.Yuvara, S.Sathishkumar and R.Nagarajan, "Modelling and Simulation of High Gain Hybrid Boost Converter," International Journal of Emerging Technologies in Engineering Research (IJETER), Volume 5, Is sue 6, pp. 9- 14, June-2017

[4] Farrukhehtisham,"performance evaluation of secure video transmission over wimax", international journal of computer networks \& communications (ijcnc) vol.3, no.6, november 2011

[5] Dr.R.Nagarajan, S.Sathishkumar, K.Balasubramani, C.Boobalan, S.Naveen and N.Sridhar. "Chopper Fed Speed Control of DC Motor Using PI Controller," IOSR- Journal of Electrical and Electronics Engineering (IOSR- 
JEEE), Volume 11, Is sue 3, Ver. I, pp. 65-69, May

- Jun. 2016.

[6] M. Sridhar, S.Sathishkumar, R.Nagarajan and R.Yuvaraj, "An Integrated High Gain Boost Resonant Converter for PV System," International Journal of Emerging Technologies in Engineering Research (IJETER), Volume 5, Issue 6, pp. 54- 59, June-2017.

[7] R.Prabhu, R.Nagarajan, N.Karthick and S.Suresh, "Implementation of Direct Sequence Spread Spectrum Communication System Using FPGA," International Journal of Advanced Engineering, Management and Science (IJAEMS), Vol-3.Issue5, pp. 488-496, Мay. 2017

[8] Guocheng liu, nezih mrad,and dayan ban department of electric and computer engineering," rf-based power transmission for wireless sensors nodes", smart materials, structures \& ndt in aerospace conference ndt in canada 20112 - 4 November 2011, montreal, quebec, canada

[9] R.Nagarajan, R.Yuvaraj, V.Hemalatha, S.Logapriya, A.Mekala and S.Priyanga, "Implementation of PV - Based Boost Converter Using PI Controller with PSO Algorithm," International Journal of Engineering And Computer Science (IJECS), Volume 6, Is sue 3, pp. 20479-20484, March, 2017.

[10] M.Meenakshi, R.Nagarajan, R. Banupriya and M.Dharani Devi, "Stepped Multicarrier SPWM Techniques for Seven - Level Cascaded Inverter," International Journal of Emerging Technologies in Engineering Research (IJETER), Volume 5, Issue 12, pp. 43- 49, December-2017.

[11] R.Nagarajan, S.Sathishkumar, S.Deepika,

G.Keerthana, J.K.Kiruthika and R.Nandhini, "Implementation of Chopper Fed Speed Control of Separately Excited DC Motor Using PI Controller", International Journal of Engineering And Computer Science (IJECS), Volume 6, Issue 3, pp. 20629-20633, March, 2017.

[12] Muhammad arsalan khan" rf based wireless fire security system for hospitals", ssu res .j. of engg. \& tech. vol. 2. Issue 1. 2012

[13] G. Vidhya Krishnan, R.Nagarajan, T. Durka, M.Kalaiselvi, M.Pushpa and S. Shanmuga priya, "Vehicle Communication System Using Li-Fi Technology," International Journal of Engineering And Computer Science (IJECS), Volume 6, Is sue 3, pp. 20651-20657, March 2017.

[14] R.Nagarajan, J.Chandramohan, S.Sathishkumar, S.Anantharaj, G.Jayakumar, M.Visnukumar and R.Viswanathan, "Implementation of PI Controller for Boost Converter in PV System," International
Journal of Advanced Research in Management, Architecture, Technology and Engineering (IJARMATE). Vol.11, Issue.XII, pp. 6-10, December. 2016.

[15] M.Dharani Devi and R.Nagarajan, "Implementation of Different PWM Control Strategies for Cascaded MLI," Journal of Network Communications and Emerging Technologies (JNCET), Volume 7, Issue 7, pp. 49- 55, July2017.

[16] M.i. ma'rufl,m.b. othman1, sholeh h .p" audio transmission using visible light communication (vlc)", arpn journal of engineering and applied sciences (C2006-2013 Asian research publishing network (arpn). All rights reserved.

[17] R.Nagarajan and M, Saravanan, "Comparison of PWM Control Techniques for Cascaded Multilevel Inverter" International Review of Automatic control (IRACO), Vol.5, No.6, pp. 815-828. Nov. 2012.

[18] M.Dharani Devi, M.Malarvizhi and R.Nagarajan, "Development of Multicarrier SPWM Techniques for Cascaded MLI." International Journal of Computational Engineering Research (IJCER), Vol. 7, Issue 10, October 2017, pp. 44-52.

[19] $\mathrm{R}$ Rameshkumar and $\mathrm{R}$ Nagarajan, "Sine Multicarrier SPWM Technique for Seven Level Cascaded Inverter," CiiT-Programmable Device Circuits and Systems. Vol. 5, Issue- 6, 2013.

[20] R.Nagarajan and M,Saravanan "Staircase Multicarrier SPWM Technique for Nine Level Cascaded Inverter," 2013 International Conference on Power, Energy and Control (ICPEC), IEEE Press, pp-668-675. 2013.

[21] Irfanullah1, amjad ali, Abdul qadir khan, rehanullah khan," wimax based audio/video transmission", ijcsi international journal of computer science issues, vol. 10, issue 1 , no 3 , January 2013 issn (print): 1694-0784 | issn (online): 1694-0814www.ijcsi.org

[22] R.Nagarajan and M, Saravanan. "Performance Analysis of a Novel Reduced Switch Cascaded Multilevel Inverter," Journal of Power Electronics, Vol.14, No.1, pp. 48-60, Jan.2014.

[23] S.Suresh, R.Nagarajan, R.Prabhu and N.Karthick, "Energy Efficient EO Algorithm for Wireless Transceivers," International Journal of Engineering and Computer Science (IJECS), Volume 6, Issue 7, July 2017, pp. 2198221985, DOI: $10.18535 /$ ijecs/v6i7.15.

[24] R. Banupriya, R.Nagarajan, M.Malarvizhi and M.Dharani Devi, "Multicarrier - Based PWM Control Strategies for Five - Level CMLI." Journal 
of Network Communications and Emerging

Technologies (JNCET), Vol. 7, Is sue 11, November - 2017, pp. 33-39.

[25] Http://searchnetworking.techtarget.com/defi nition/radio-frequency

[26] R.Nagarajan, J.Chandramohan, R.Yuvaraj, S.Sathishkumar and S.Chandran, "Performance Analysis of Synchronous SEPIC Converter for a Stand-Alone PV System," International Journal of Emerging Technologies in Engineering Research (IJETER), Vol. 5, Issue - 5, pp. 12-16, May-2017

[27] M.Padmavathi and R.Nagarajan, "Smart Intelligent ATM Using LABVIEW," International Journal of Emerging Technologies in Engineering Research (IJETER), Volume 5, Issue 5, pp. 41- 45, May-2017.

[28] J.Chandramohan, R.Nagarajan, K.Satheeshkumar, N.Ajithkumar, P.A.Gopinath and S.Ranjithkumar, "Intelligent Smart Home Automation and Security System Using Arduino and Wi-fi," International Journal of Engineering And Computer Science (IJECS), Volume 6, Is sue 3, pp. 20694-20698, March, 2017.

[29] K. Anandhi and Dr. R. Nagarajan, "Mutex-Heart: Fail Safe Dual Chamber Cardiac Pacemaker Device with Rate Responsive Control and Cryptographic Security," IJSRD- International Journal for Scientific Research \& Development. Vol. 3, Issue- 2, pp. 489-493, 2015.

[30] M.Malarvizhi, R.Nagarajan, M.Meenakshi and R. Banupriya, "Unipolar Sine Multicarrier SPWM Control Strategies for Seven - Level Cascaded Inverter," International Journal of Emerging Technologies in Engineering Research (IJETER), Volume 6, Issue 1, pp. 111- 117, January-2018.

[31] J.Chandramohan, R.Nagarajan, M.Ashok kumar, T.Dineshkumar, G.Kannan and R.Prakash, "Attendance Monitoring System of Students Based on Biometric and GPS Tracking System," International Journal of Advanced Engineering, Management and Science (IJAEMS), Vol-3.Issue3, pp. 241-246, Mar. 2017.

[32] N.Karthick, R.Nagarajan, S.Suresh and R.Prabhu, "Implementation of Railway Track Crack Detection and Protection," International Journal Of Engineering And Computer Science (IJECS), Volume 6, Issue 5, May 2017, pp. 2147621481, DOI: $10.18535 /$ ijecs/v6i5.47

[33] S.Sathishkumar, R.Nagarajan, R.Yuvaraj, M. Sridhar and M.Elangovan, "Implementation of Pwm Technique For Integrated High Gain” IOSR Journal of Engineering (IOSRJEN), Vol. 08, Issue 3, PP. 59-66, March - 2018.
[34] S.Suresh, R.Nagarajan, L.Sakthivel, V.Logesh, C.Mohandass and G.Tamilselvan, "Transmission Line Fault Monitoring and Identification System by Using Internet of Things," International Journal of Advanced Engineering Research and Science (IJAERS), Vol - 4.Issue - 4, pp. 9-14, Apr- 2017. 